\title{
Das zonas francas e sua importância na atualidade: os exemplos de Manaus e a Terra do Fogo
}

Free trade zones and their importance in current times: the examples of Manaus and Tierra del Fuego

Nara Shirley de Sousa Costa [I]

\section{Resumo}

No contexto em que se discute, no plano da política econômica nacional, a extinção da Zona Franca de Manaus- ZFM sob o pretexto dos seus custos fiscais, o presente estudo mostra a existência de várias zonas francas existentes pelo mundo. Tal compreensão permite verificar como uma forma específica de articulação entre diversos agentes sociais contribui na constituição de lugares-chave para a transnacionalização do capital. A ZFM e a Área Aduaneira Especial da Terra do Fogo - AAE/TDF mostram que cumpriram seus objetivos primordiais referentes à ocupação e à modernização com impactos de várias ordens. Contudo a interrogação que se faz é qual o sentido da existência desses mecanismos no contexto contemporâneo.

Palavras-chave: Zona Franca de Manaus; Área Aduaneira da Terra do Fogo; investimentos externos diretos; zona econômica de exportação; China.

\begin{abstract}
The extinction of the Manaus Free Trade Zone (MFTZ) on the pretext of its tax costs has been discussed in the sphere of Brazil's national economic policy. In this context, our study presents several free trade zones that exist across the world. Such understanding allows to verify how a specific form of articulation between different social agents contributes to the constitution of key places for the transnationalization of capital. The MFTZ and the Tierra del Fuego Special Customs Area (TDF/SCA) show they have fulfilled their primary objectives regarding occupation and modernization, with impacts of various types. However, the question arises as to the meaning of the existence of these mechanisms, as they play a fundamental role in their regions.
\end{abstract}

Keywords: Manaus Free Trade Zone; Tierra del Fuego special customs area; foreign direct investment; export processing zone; China. 


\section{Introdução}

0 olhar sobre as zonas francas permite verificar como uma forma específica de articulação entre diversos agentes sociais colabora na constituição de lugares-chave para a transnacionalização do capital. A compreensão paira nas definições, práticas e interesses ligados por modalidades econômicas e políticas adaptadas nas diversas fases ou configurações do capitalismo. 0 texto destaca a Zona Franca de Manaus - ZFM e a Área Aduaneira Especial da Terra do Fogo - AAE/TDF, na Argentina.

Para entender o processo, é necessário ater-se às mudanças ou à reorganização do sistema mundial, provocado por novas formas de regulação em que vários agentes exercem papel fundamental para a arquitetura da economia mundial e que podem ser vistas, conforme Michalet (2003), em resumo, nas três configurações do desenvolvimento do capitalismo: 1) Internacional, 2) Multinacional e 3) Global.

A primeira configuração do capitalismo é a internacional; ela se refere às trocas comerciais, ou seja, da especialização internacional e perdurou até os anos de 1960, centralizada no poder do Estado-Nação. A segunda é a multinacional, das décadas de 1960-1980, e move-se na lógica da competitividade, do aumento dos fluxos materiais e financeiros, da regulação mista entre o Estado e as empresas, da propagação dos Investimentos Diretos Externos IDE e da mobilidade da produção dos bens e serviços, em que as empresas multinacionais são atores predominantes. A terceira é a global, da dimensão financeira, das aplicações das empresas no mercado financeiro, cujos atores principais são instituições financeiras privadas, companhias de seguro, fundos de pensão, entre outros (ibid.).
Em cada configuração, ocorreram formas de regulação específicas, e as consequências são observadas na dinâmica econômica no que tange à reestruturação produtiva, como nas infraestruturas espaciais, e permitiram que os fluxos de capital fluíssem deliberadamente em várias interações (ibid.).

Várias questões prescindem das zonas francas e exigem pesquisas que combinem elementos de ordem qualitativa e quantitativa. Na constituição deste artigo, a pesquisa documental e bibliográfica foi fundamental. Assim, dos trabalhos que compõem o aporte teórico deste texto se destacam Khanna (2016 e 2019), Sassen (1998 e 2010), Sklair (1989 e 1995), Freitas Pinto (1987); Seráfico e Seráfico (2005); e Seráfico (2009). Os dados quantitativos e as estatísticas oficiais se compõem como fontes secundárias de relatórios de organizações internacionais, os quais apresentam a identificação das condições estabelecidas por meio das interações de diretrizes globais na promoção e uso das zonas francas.

A Complexidade Econômica concerne no aporte qualitativo de apoio para este estudo. Essa abordagem sustenta que a economia não está necessariamente no equilíbrio; embora a matemática seja útil para economia, não se trata de algo dado e existente, mas se forma a partir de um fluxo constante, desenvolvido no conjunto de instituições, arranjos e inovações tecnológicas. Logo, os agentes econômicos ajustam continuamente seu comportamento, o que pode ser demonstrado na composição de um sistema complexo, no qual múltiplos elementos se adaptam ou reagem a regras que os próprios sistemas criaram (Arthur, 2013).

Destarte, o Atlas de Complexidade Econômica (Hausmann et al., 2013) e Gala (2017) são fontes elucidativas de insights. 0 Atlas 
apresenta o Índice de Complexidade Econômica - ICE, que se trata do nível de desenvolvimento da estrutura produtiva de um país ou de uma região geográfica. Nesse panorama, a complexidade dos sistemas econômicos complexos está correlacionada a uma abordagem empírica, emersa de ampla base de dados (Big Data) ${ }^{1}$ (Hausmann et al., 2013). Gala (2017), ao usar o Atlas procura responder questões basilares da economia: como se explicam o desenvolvimento econômico, a questão da pobreza e a riqueza dos países. Para tanto, aliado a uma série de dados, faz uma digressão entre autores estruturalistas do pensamento econômico ${ }^{2}$ e alude à questão da especialização produtiva das nações, remetendo, assim, à premissa de que "Países ricos são ricos porque produzem bens complexos, países são pobres porque produzem bens não complexos" (ibid., p. 53).

Logo, o presente artigo ajuda a pensar como as zonas francas se constituíram e se ajustaram nas articulações dos governos, conjunto de instituições, arranjos e inovações tecnológicas, situando-as na divisão do trabalho internacional e/ou nas políticas econômicas que procuram privilegiar a abertura comercial e a desregulamentação dos mercados em diversas partes do mundo, ou seja, na agenda neoliberal.

Destarte, 0 artigo se divide em três partes, a primeira com a contextualização histórica e social das zonas francas. A segunda situa a implantação das zonas francas de Manaus e da Patagônia e traz uma breve caracterização dos resultados para as respectivas regiões, aspectos estes demonstrados por meio de dados socioeconômicos. A última parte trata dos desafios das zonas francas na constituição e/ou integração de cadeias globais de valor - CGV e na conectividade dos lugares; elas, por sua vez, sofrem os impactos das dimensões territoriais mediante as possibilidades de inserção internacional das economias locais. Os exemplos das cidades globais ou cidades com zonas francas ou equivalentes são pertinentes.

As informações relativas à ZFM e à $A A E$ da Terra do Fogo mostram que elas não são algo tão extraordinário, em razão da multiplicidade, e se relacionam aquém e além do que representam para suas regiões (dada à importância histórica, social e política), mas esbarram nas transformações e nos desafios que enfrentam, não somente relativos às datas de validade, mas também à competitividade, complexidade econômica e dos impactos sociais, urbanos e ambientais.

\section{Contextualização histórica e social das zonas francas}

Dados de 2019 do Relatório de Investimento Mundial ${ }^{3}$ registram ${ }^{4}$ que "existe cerca de 5.400 zonas em 147 economias, em comparação às 4.000 que existiam há cinco anos (mais de 1.000 foram estabelecidas nos últimos cinco anos) e mais de 500 novas ZEEs estão em processo de planejamento de implantação" (WIR, 2019, p. 128).

A Corporação Financeira Internacional - CFI define Zona Econômica Especial - ZEE como "áreas geograficamente delimitadas e administradas por um organismo único e oferecem certos incentivos (duty-free, isenção de importação ou procedimentos aduaneiros simplificados) para empresas localizadas na zona" (Fias, 2008, p. 2). Para a Organização Internacional do Trabalho - OIT, "são áreas industriais dotadas de incentivos fiscais especiais para 
atrair investidores estrangeiros, em que os materiais importados sofrem algum grau de transformação antes de serem reexportados" (llo, 2003, p. 7).

De modo geral, a legislação é específica e possibilita tratamento diferenciado do restante do território nacional onde está localizada, ou seja, são áreas dentro do território de um Estado nacional, marcadas por regimes fiscais específicos relativos a incentivos ou isenções fiscais e que dispõem de condições de estabilidade política, redução de entraves burocráticos, redução dos custos de implantação por meio do aporte de infraestrutura, logística, incentivos fiscais e oferta de mão de obra barata, entre outros.

A análise em termos quantitativos, no Facility for Investment Climate Advisory Services - Fias Annual Review de 2008, mostra que, nessas "zonas", foram gerados mais de 68 milhões de empregos diretos e foram movimentados mais US\$500 bilhões com 0 comércio direto. Para Fias (2008) as ZEEs constituem "ferramenta útil para os países em desenvolvimento" como estratégia de inseri-los em uma economia global, proporcionando-Ihes competitividade, absorção de novas tecnologias, geração de empregos e atração de IDE (ibid., p. 7).

Basicamente, as zonas francas são classificadas em: Porto Livre (porto franco); Zona de Processamento de Exportação - ZPE; Zonas Econômicas Especiais - ZEEs (China); armazéns aduaneiros; Zona de Livre Comércio - ZLC; armazéns alfandegários (bonded warehouses); armazéns fiscais; centros offshore; ${ }^{6}$ Foreign Trade Zones - FTZ (EUA); paraísos fiscais (ex. Bahamas e Mônaco); maquiladoras (México); zonas francas urbanas (França); e outras designações (Ilo, 2003; e WIR, 2019).
Os diversos tipos decorrem das formas de atuação, sejam dos objetivos ou dos setores para os quais funcionam, por exemplo: indústria, serviços, logística, porto franco, turismo e outros. Como também "os países tendem a adotar tipos específicos de ZEEs de acordo com seu estágio de economia em desenvolvimento". Portanto, não há um modelo institucional uniforme devido a essa gama de atuações (WIR, 2019, p. 140).

O primeiro "modelo de zona livre moderna foi implantado no aeroporto de Shannon (Irlanda), em 1959, e foi transformado em Shannon Free Industrial Zone" (Fias, 2008 , p. 3). Fias (ibid.) e Vives (2000) situam a concepção de tipos semelhantes às zonas francas nos regimes aduaneiros dos fluxos de comércio e navegação. Segundo Vives (ibid.), no século XVIII, a peculiaridade de introduzir mercadorias estrangeiras com isenções de impostos ocorria esporadicamente nos períodos de feira, e gradativamente tipos similares surgiram na facilitação do comércio e da navegação.

Diversos países investiram na instalação das zonas, dentre eles: o Líbano e Panamá (1948), Uruguai (1949), Angola (1950), Síria (1942), Áustria (1955), Brasil (1957), Líbia (1959), Taiwan (1966), Singapura (1969), República da Coréia (1970), e tinham como prioridade de seus governos a expansão comercial. Até 1975 , todas as zonas eram de propriedade do governo, atualmente elas podem se compor por zonas francas públicas, privadas e de regime misto (Parceira Público-Privada - PPP) (Fias, 2008, p. 23).

Para Sklair (1989), zonas francas ou offshores são locais privilegiados que permitem a transferência de capital atraído por uma série de incentivos, como: isenções fiscais 
parciais ou totais, vasta oferta de mão de obra barata, liberdade de câmbio e estratégia de fuga das pressões trabalhistas.

É notável que a difusão das zonas francas encontre maior vigor após a II Guerra Mundial, quando, a partir da década de 1960, o processo de mundialização realçou o novo aspecto da divisão do trabalho. Assim, foram inseridas as áreas descolonizadas, possibilitando que países afro-asiáticos adentrassem nos processos de modernização sociopolítica de suas economias. Tais processos foram pautados por contradições e, consequentemente, colocaram os países do Terceiro Mundo nas metas de industrialização, concebidas a partir das estratégias de industrialização do Primeiro Mundo (Sklair, 1989).

Em alguns casos, esses processos foram viabilizados por zonas francas (ibid., p. 4), nas quais as empresas procuravam "a garantia de governos fortes, sobretudo à questão do controle da classe trabalhadora, particularmente em relação à atuação de sindicatos e à perspectiva de movimentos grevistas" (Freitas Pinto, 1987, p. 24). Logo, o desenvolvimento de nova divisão internacional do trabalho retrata a tendência da influência de determinados países sobre certas regiões do mundo e se estruturou nos seguintes eixos: empresas japonesas deslocaram-se para outras regiões da Ásia, e empresas europeias estabeleceram-se em regiões da África, enquanto as empresas norte-americanas visaram países do Caribe e da América do Sul.

Para promover as zonas francas, a Organização das Nações Unidas para o Desenvolvimento Industrial - Onudi, em 1972, realizou o "Seminário de treinamento sobre Zonas Francas Industriais" em Shannon
(Irlanda). O documento Industrial Free Zones as Incentives to Promote Export-Oriened Industries, discutido no evento, aponta que, em 1971, havia no mundo apenas três exemplos de ZEE: Kaoshiung (China), Shannon (Irlanda) e Kandla (Índia) (Seráfico e Seráfico, 2005).

Conforme, Freitas Pinto (1987, p. 26), o seminário apresentou aos países as principais características das zonas que, do ponto de vista "técnico, organizativo, espacial e legislativo", foram estruturadas pela Onudi e serviram de modelo mundial para as zonas francas industriais. $E$, dentre os resultados do seminário, 30 países em desenvolvimento - PED anunciaram "planos de criar em seus territórios esse tipo de mecanismo de dinamização econômica" (ibid., p. 104).

Conforme, dados da OIT, o crescimento de países que adotaram as zonas, delineado na inserção de novas regiões no processo de produção, circulação e consumo do capital, pode ser visto nos seguintes números, em 1975 existiam 79 zonas, em 25 países; em 1986: 176 em 47 países; 1997: 845 em 93 países; 2002: 3.000 em 116 países; 2006: 3.500 em 130 países (Ilo, 2003). Em termos de empregabilidade, na década de 1970, empregavam cerca de 800 mil pessoas; 30 anos depois, o número ultrapassou os 65 milhões de empregados (Fias, 2008, p. 23).

Assim, o processo transnacional da manufatura para os "países periféricos" ou "economias em transição" demarcou a mobilidade de capital, produção e serviços das empresas e IDE. A industrialização mundial conjuga-se a "um sistema de atividades econômicas para as quais os territórios e fronteiras de Estados não constituem o esquema operatório básico, mas apenas complicadores" (Hobsbawn, 1995, p. 272). 
Para Michalet (2003), o processo estruturou-se na regulação mista (Estados-empresas transnacionais), ou seja, nos acordos entre os governos e os atores privados; e trouxe outra formatação da divisão do trabalho e da produção, que reformulou e/ou complementou o modelo fordista, ${ }^{7}$ isto é, passou da produção em série (representada no chão de fábrica) ${ }^{8}$ para a etapa do capitalismo de reformulações no sentido geográfico da produção. A base de sustentação fordista-keynesiana deixa de ser o centro da produção dos países industrializados e é transplantada para formatos mais flexíveis em diferentes lugares no mundo (Sklair, 1989).

A redução dos custos salariais, geração de empregos, aquisição de divisas e novas tecnologias eram objetivos vinculados às zonas francas (Fias, 2008) e se constituíam alternativas de deslocalização da produção, articuladas aos avanços tecnológicos nos modos de produção. As empresas, ao transcenderem o locus de origem, visando à redução de custos de produção e alcance à maior competitividade, envolveram-se em processos cada vez mais complexos, o que se somava às novas formas de investimento (Chesnais, 1996) e ao uso das tecnologias de informações e comunicação (Castells, 2006).

Como novas formas hierárquicas de concentração e expansão econômica, as zonas francas formatam-se como espaços desnacionalizados, pautando redefinições de processos espaciais e de territorialização de novas áreas com novos elementos que, ao se estabelecerem na agenda de políticas nacionais de desenvolvimento via industrialização, implicaram a desagregação de estruturas tradicionalmente constituídas, mediante adequação às (novas) racionalizações, as quais respondem ao conjunto de processos, serviços, inovações tecnológicas e normas decorrentes de novas formas regulatórias de alcance internacional (Sassen, 1998 e 2010).

Marcam o aparecimento dos países em recente industrialização nos quais as estratégias de industrialização de países periféricos sistematizaram uma rede de ZPE na África e América Latina. $O$ caso do Leste Asiático, Hong Kong, Cingapura, Coréia do Sul e Taiwan se diferencia das estratégias da Industrialização por Substituição de Importação - ISI dos latino-americanos, pois eles se voltaram para as "exportações de manufaturados. Esses competitivos em alguns produtos e, assim, ganharam o crescimento estrangeiro suficiente" (Sklair, 1989, p. 4).

Dos resultados, a Ásia, ao estabelecer ZEE em parte, contribuiu para seu crescimento econômico das últimas décadas, com a implantação de ZPE, na Coréia do Sul e em Taiwan, a partir de 1960 e 1970, especializando-se na produção de componentes eletrônicos e produtos têxteis. A Coréia do Sul destaca as ZPE de Masan (1970) e Iri (1973); Taiwan localiza as ZPE de Kaohsiung (1966), Nantze, Taichung (1970) e a de Hsinchu (1980), esta concebida como science-based industrial park para a fabricação de produtos de alta tecnologia. 0 país também se destaca por mais 3 zonas de parques ambientais de Ciência e Tecnologia C\&T e outras 3 ZEEs especializadas em biotecnologia agrícola e estratégia de modernização industrial de alto valor agregado, implantadas no início do século de XXI (WIR, 2019).

Dentre os países asiáticos, o caso mais emblemático é o da China, pois, com o início de sua reforma econômica, em 1978, definida na política de abertura ao exterior, planificada, controlada e gradual, dentre outras medidas, deu-se a criação de espaços para a captação 
de capitais, conhecimento, tecnologia e mão de obra qualificada. Destarte, as primeiras ZEEs localizadas na região costeira (Shenzhen, Zhuhai, Sahantou e Xiemen) objetivaram produzir para a exportação, geração de empregos e divisas.

Em 1980, Shenzhen torna-se a primeira ZEE. Além de constituir o laboratório da experiência capitalista na China comunista de Deng Xiaoping, a partir da sua implantação alcançou a taxa de crescimento anual de 30\% (Khanna, 2016), alterando-se de uma vila de 30.000 habitantes para 12 milhões em 2018. Dados de 2018, sobre o seu Produto Interno Bruto - PIB, registram US\$491 bilhões, o que a constitui como a quarta maior economia e maior renda per capita do país. Sua plataforma de produção voltada para tecnologia a faz conhecida como a "capital mundial de inovação em hardware" e é nela que se localiza a segunda principal bolsa de valores da China. Seus investimentos em Pesquisa \& Desenvolvimento - P\&D equivalem ao dobro da média nacional, com 4,05\% do PIB da cidade, termos semelhantes aos da Coréia do Sul (Geromel, 2019, s. p.).

De acordo com WIR (2019, p. 143), a partir dos anos 2000, a China expandiu as ZEEs para o interior e região Oeste. Cabe enfatizar que o país detém mais da metade das ZEEs existentes no mundo, e três quartos das que estão na Ásia. Outros números são ilustrativos, pois são responsáveis por $22 \%$ do PIB do país, representam cerca $46 \%$ dos IDE e $60 \%$ das exportações (Khanna, 2016). Segundo dados do WIR (2019, p. 179), "as ZEE são responsáveis por mais de 80 por cento do IDE acumulado".

Vistas em um quadro global, a maioria das zonas está na Ásia e no Pacífico e estima-se que o número ultrapasse 900. Além disso, "são responsáveis por aproximadamente \$200 bilhões de dólares em exportações por ano e empregam diretamente mais de 40 milhões de trabalhadores e cerca de 60 milhões indiretamente" (Fias, 2008, p. 23). Khanna (2016) aponta que a "Ásia possui mais de $85 \%$ de todos os trabalhadores das ZPEs em todo o mundo", e a Índia possui 143 ZEEs funcionais, das quais um quarto se localiza no setor de Tecnologia da Informação. Países que mais utilizam esses mecanismos são China, Estados Unidos, Índia e Filipinas (WIR, 2019).

Em relação aos IDEs, dados do WIR (2019, p. 180) atestam que "as ZEEs são um destino importante de IDE em muitos países" e citam que, na Malásia, quase $90 \%$ do investimento total são de IDE; no Vietnã, esse número varia entre 60 e 70\%; em países de baixa renda, como Camboja e República Democrática Popular do Laos, as "zonas atraem quase exclusivamente investimentos estrangeiros e respondem por uma parcela significativa do IDE total"; e em Bangladesh, representam 72\%.

Para Sklair (1989), o processo de modernização, abertura às portas ao capital estrangeiro por meio da criação de parques industriais orientados para as estratégias de terceirização no exterior, pontuou a "reforma do capitalismo" do México, que atendia aos interesses das corporações norte-americanas. A partir de 1965, as corporações norte-americanas encontraram nas maquiladoras mexicanas, além de todas as vantagens semelhantes às ZPEs do Leste Asiático, um atrativo a mais, relativo às vantagens de logística em função da localização fronteiriça do México e EUA.

As maquiladoras no início dos anos 1970 se centravam em produtos têxteis e vestuário, mas, ao longo dos anos, diversificam-se com eletrônicos, autopeças, artigos para escritório, esportivos, móveis, brinquedos, máquinas e 
equipamentos. Na década de 1980, a pauta de exportação mexicana era liderada por dois segmentos: petróleo, seguido pela produção das maquiladoras. Assim, partiam da estratégia enquanto país fornecedor ao maior mercado consumidor do mundo, os EUA (Sklair, 1989; 1995).

Conforme Braga (1995, p. 11), em 1992, existiam 2.063 maquiladoras instaladas em 29 das 32 unidades federativas do México, 72\% localizam-se nas cidades fronteiriças com os EUA e empregavam quase meio milhão de trabalhadores, o correspondente "a 17\% do emprego total do setor industrial" com receitas que ultrapassaram US\$4 bilhões.

Dupas $(2005$, p. 66) afirma que "as maquiladoras, atividades de montagem das corporações dos EUA, utilizando de mão de obra barata local" geraram cerca "de 800 mil postos de trabalho entre 1994 e 2001; mas perderam cerca 250 mil desde maio de 2003, em razão da imbatível contraofensiva chinesa, fornecendo trabalhadores mais qualificados e a custo muito inferior". Dados de 2008 mostram 3.700 fábricas, empregando mais de 1 milhão de pessoas, com exportações de US\$80 bilhões por ano, com produção diversificada e IDE oriundos do Japão e EUA; e seus "concorrentes-chave" são "as zonas da China, ao invés de outras zonas da região". Desde 2000, as exportações chinesas deslocaram grande parte de produtos mexicanos "e se tornaram a segunda mais importante fornecedora para o mercado norte-americano (Fias, 2008, p. 26).

Outros países do continente americano têm zonas francas de diversos tipos, segundo Khanna (2016); a República Dominicana registra mais de 100.000 empregos, "sendo os EUA seu principal mercado de exportação". Sobre os EUA cabe expor que, em 2014, eles possuíam $179 \mathrm{FTZ}$ com 420 mil postos de trabalho em cerca de 2.700 empresas. De acordo o WIR (2019), o número de FTZ norte-americanas aumentou para 262.

No outro extremo, a China investe em zonas na África: em 1999, assinou com o Egito o acordo de criação da zona industrial do Canal de Suez, e, em 2006, no âmbito de 11ㅇ Plano Quinquenal, estabelecia a criação 50 ZEEs no exterior, destas 7 na África. No âmbito do Belt and Road Initiative - BRI (Iniciativa do Cinturão e da Rota) ${ }^{9}$ e do Programa de Cooperação Econômica da China no Exterior, em 2016, a China assinou a criação da FTZ em Djibuti; ${ }^{10}$ além da China, a Turquia em 2015 assinara acordo de criação de ZEE em Djibuti, visando o mercado da África Oriental para exportações e mercados regionais. $O$ Japão também ajudou a construir ZEE no Oriente Médio e África (ibid.).

No continente africano, a adoção significativa das zonas francas deu-se nas décadas de 1990 e 2000, exceções são Maurício, Gana e Libéria e remontam à década de 1970; 237 zonas estimadas, segundo o WIR (ibid.), são encontradas em 38 das 54 economias do continente, com destaque para o Quênia com 61 ZEE.

Diante do quadro geral, embora sucinto das zonas francas, o texto a seguir traz a ZFM e a Área Aduaneira Especial da Terra do Fogo. Ambas surgiram em um contexto semelhante, porém tiveram trajetórias diferentes (Alvarez, 2016). Em razão disso, apresentaremos uma breve caracterização das consequências e/ou resultados dessas zonas para suas regiões. 


\section{Do contexto das Zonas Francas de Manaus e da Patagônia}

Os planos de desenvolvimento para as regiões da Patagônia e da Amazônia, mediante zonas francas, datam do mesmo período, fim da década de 1960 e início da década 1970, com objetivos semelhantes, assim como também características semelhantes, tais como abundância em recursos naturais, ${ }^{11}$ fragilidade às questões da soberania nacional, baixa densidade populacional e atraso econômico (ibid.). Essas regiões esbarravam nas disparidades de desenvolvimento regional e baixa articulação com mercado nacional. Para dirimirem as desigualdades regionais, foram implantadas zonas francas focadas na produção de eletroeletrônicos, que serviram "como laboratórios ideais para a experimentação desses modelos" (ibid., p. 130).

Para compreender como essas regiões são inseridas no processo transnacional de manufaturas, é preciso ter em mente que, no fim do século XIX e início do século XX, a Amazônia sublinha uma economia próspera, demarcada no ciclo do látex, ${ }^{12}$ o qual ratificava sua incorporação "ao mercado internacional como provedora de bens primários"; enquanto a Patagônia, até o início da década de 1960, dependia da agricultura de subsistência, de frutas e verduras no Rio Negro, produção de lã e extração de hidrocarburos (este ainda importante) e posição estratégica do estreito de Magalhães como única conexão navegável entre o oceano Atlântico e o Pacífico (ibid.).

Aliado ao relativo isolamento geográfico e das questões geopolíticas daquele contexto histórico, está o fato de que nessas regiões quase não existia processamento local de suas matérias-primas de modo expressivo, salvo poucas exceções. Para Alvarez (ibid. p. 132), tais perspectivas, do início do século $\mathrm{XX}$ ou mais tarde, com as zonas francas, no caso da Patagônia, traduzem "a dependência externa somada a ausências de encadeamentos produtivos próprios ao interior" e demarcam o ciclo repetitivo, "logrando fases de auge, enquanto o estímulo externo permanece, e caídas pronunciadas quando este deixa de existir. Os lucros obtidos em cada ciclo se externam, e por isso não são acumuladas na própria região".

Ademais, no fervor do discurso militar de integração, ${ }^{13}$ a Argentina precisava proteger as Ilhas Maldivas dos interesses ingleses e das disputas territoriais da fronteira com o Chile; ${ }^{14}$ enquanto, na região Norte do Brasil, projetos nacionais visavam a integrar a região", considerada "vazio demográfico", improdutivo à economia nacional. A "Operação Amazônia 1965/1967" compõe uma das tentativas de "instaurar a região de rentabilidade econômica global" (Seráfico e Seráfico, 2005). Logo, sua posição estratégica se ajustava nas preocupações de sua incorporação ao território nacional. Manaus nesse contexto, especificamente com a ZFM, surgiria como um enclave para a interligação financeira e comercial com as demais regiões do País, bem como para sua articulação no âmbito internacional.

Assim, a lógica de transnacionalização e intensificação das relações sociais e materiais, que teceram a implantação da ZFM em 1967, condicionada, entre outros fatores, por IDE e pelas políticas de incentivos do Estado brasileiro, ou seja, a política desenvolvimentista para essa parte da Amazônia, seguia o modelo das políticas de ISI, adotado por muitos países no pós-II Guerra Mundial e que incidiu no aumento da produção interna do País, mediante 
a diminuição de suas importações, aliado ao controle das taxas de importação e manipulação das taxas de câmbio.

A abordagem, de certo modo, partia da influência da Comissão Econômica para América Latina - Cepal, que serviu de modelo para países da América Latina, p. ex. Brasil, México e Argentina, como também para países da África, e que se resumia na premissa: produzir internamente tudo o que antes era importado. Assim, a política macroeconômica adotada pelos países latino-americanos era marcada com "forte viés para apreciações cambiais" e elevadas tarifas de importação (Gala, 2017, p. 83).

Becker (2005), ao expor sobre geopolítica da Amazônia, pontua que as formas de ocupação da região devem ser vinculadas à compreensão da lógica dos projetos de desenvolvimento e a suas especificidades, das mudanças estruturais, conflitos e outros fatores, segundo os quais a Amazônia não pode ser concebida como espaço homogêneo, mas na coexistência de diferentes atores nas diversas escalas, em que o Estado não é a único detentor dos instrumentos de poder como outrora.

Desse modo, o papel do Estado no processo de modernização da região pontuou as diretrizes que miravam o aniquilamento de experiências de planejamento de pouco êxito, como o Banco de Crédito da Amazônia e a Superintendência Executiva do Plano de Valorização - SPVEA e que se pautavam na superação da economia extrativista (Brito, 2011). Resumidamente, objetivaram estabelecer polos de desenvolvimento, estimular a imigração e dar incentivos ao capital privado, o que resultou, dentre outras atividades, na expansão da atividade primária em Rondônia, na instalação da
ZFM e na construção de grandes projetos de mineração e infraestrutura de energia no estado do Pará (Mahar, 1978).

A Amazônia, para Mahar (ibid.) como "fronteira de recursos" deveria ser protegida das possíveis "ameaças estrangeiras"; a promoção de desenvolvimento e ocupação humana atrelou o surgimento "de novas vias de comunicações e transportes, colonização agrícola" e atração de investimentos privados por meio dos incentivos fiscais e monetários. Dentre os resultados, o Plano de Integração Nacional pôs em pauta a abertura de estradas como a Transamazônica, a BR-163 (Santarém-Cuiabá) e a BR-319 (Manaus-Porto Velho); embora tais pavimentações não tenham se concretizado por completo, elas se atrelavam às alegações de "controle territorial", observáveis em frases como "integrar para não entregar" em voga na época.

Segundo Alvarez (2016, p. 119), a ZFM e a AAE da Terra do Fogo resultam de planos de promoção industrial projetados para ratificar a ocupação efetiva do Estado, ou seja, "era a prolongação da conquista militar por outros meios", com consequências de ordem socioambiental, cultural e econômica, transformando a estrutura dessas regiões, tanto em termos demográficos quanto sociais.

Tais regiões podem ser vistas nos escalonamentos hierárquicos da globalização. Nesse sentindo, as análises de Seráfico (2009, p. 50) sobre a ZFM permitem perceber como a "complexa trama de relações que ajudam a estruturar a configuração do capitalismo" estão entrelaçadas nas dinâmicas dos baixos e altos circuitos do capital.

Assim, no quadro em que se "entrecruzam forças sociais transnacionais, nacionais e locais", a constituição de "espaços globais", 
como as zonas francas, e o engajamento dos agentes locais às demandas "originárias do processo de reprodução ampliada do capital só adquirem consistência histórica em virtude de mobilizarem agentes que se situam nos "baixos circuitos do capital" (ibid., p. 84)

Com esse cenário, pode se dizer que, no intuito de atender a vários interesses e em diferentes escalas e escopo, a ZFM, em Manaus, contou com o apoio das elites locais e, em certo sentido, via-se órfã do período áureo da borracha e insatisfeita no aparente "descaso" do poder central com a falta de medidas de inserção da região no processo de "desenvolvimento nacional fundado na industrialização por meio da substituição de importações" (Seráfico e Seráfico, 2005, p. 100).

Logo, era necessário dar um novo fôlego. Então, a ideia de "retomada da economia" reluzia ao "surgimento de novas oportunidades de negócios decorrentes dos atrativos da ZFM e eram sinais da emergência de novas condições de inserção econômica do empresariado local" (Seráfico, 2009, p. 114), além de poder satisfazer, embora em parte, tais expectativas. Estas, em Manaus, resultaram em mudanças sociais que diluíram o paradigma econômico tradicional, proveniente da coleta de recursos da floresta, transformando-o no modelo baseado na ZFM, "que foi um posto avançado geopolítico colocado pelo Estado na fronteira norte, em pleno ambiente extrativista tradicional" (Becker, 2005, p. 73).

Assim, a Amazônia Ocidental, onde se localiza Manaus, erigia-se sob o modelo de industrialização e, assim, consolidava-se dentre diferentes modelos voltados para o desenvolvimento da Amazônia brasileira, que, por sua vez, resultaram em desdobramentos nas diferentes escalas em que Estado, empresas e movimentos de resistência se relacionavam em diferentes contextos da Amazônia (ibid.).

No outro extremo, mudanças são vistas na parte sul da Argentina, na Grande Ilha da Terra do Fogo, ${ }^{15}$ decorrentes da implantação da área aduaneira especial: das 7 mil pessoas registradas na década de 1960 passou-se, em 2001, a mais de 100 mil habitantes; crescimento de mais de 14 vezes; e, apesar da baixa densidade, dados do censo de 2010 atestam que os três principais centros urbanos (Ushuaia, Rio Grande e Tolhuin) concentram mais de 90\% dos 127, 205 mil habitantes (Indec, 2019). Em relação ao censo de 2000, esse número representa crescimento de $26 \%$; Ushuaia, capital da província, além de ser a cidade mais austral do mundo, está localizada no âmbito da AAE da Terra do Fogo e possui 60.000 habitantes (GOB. AR., 2017).

A região, no início da década de 1970 , ao lado do baixo nível populacional, apresentava alta proporção de estrangeiros. Com a implantação da AAE da Terra do Fogo, a proporção de nascidos localmente aumentou em relação aos nascidos no exterior (atualmente 91,1\% da população é nativa) (ibid., p. 17); outra consequência vista na década de 1980 se refere à especulação imobiliária na capital, o que, segundo Bekerman e Dulchih (2017, p. 59), traduz-se na "ocupação ilegal da terra e na proliferação de assentamentos", refletindo as más condições de vida da população.

Contudo, a lei n. 19.640, dos benefícios da promoção econômica e fiscal, constituiu a AAE Terra do Fogo como um dos principais centros industriais do país (ibid.). Embora, implantada em 1972, os impulsos significativos de promoção industrial, de acordo com a Superintendência da Zona Franca de Manaus Suframa, obtiveram 
resultados mais expressivos nos últimos anos, [mediante]maiores incentivos e o boom na produção doméstica de eletroeletrônicos e bens de informática, [sendo]responsável pela fabricação de grande parte dos eletroeletrônicos consumidos pelo mercado argentino, como televisores, câmeras e celulares, abrigando grandes marcas da indústria mundial. (Suframa, 2014, s. p.)

Conforme Bekerman e Dulcich (2016, p. 59), em 1989, os benefícios da referida lei "foram parcialmente suspensos, assim como a possibilidade de apresentar e aprovar novos projetos industriais (decreto 1927/1993)". As mudanças estruturais em nível nacional do início da década de 1990, com a "abertura, desregulamentação, privatização, ajuste fiscal, etc.", limitaram "a concessão de incentivos ao estabelecimento de empresas", ocasionando o "fim do pleno emprego na região".

Para Bekerman e Dulcich (ibid.), em termos comparativos, a Área Aduaneira Especial da Terra do Fogo possui menor diversificação (centralizado no setor de eletrônicos), escala e escopo e metade do número de fábricas ou empresas de grande porte do que a ZFM. Para a Suframa (2019), o Polo Industrial de Manaus - PIM possui mais de 500 fábricas de "alto nível tecnológico" e constitui uma das "mais modernas zonas industriais da América Latina". Consequentemente, na visão de Bekerman e Dulcich (2017, p. 774), significa maior número de empregos, tanto em nível absoluto quanto relativo, "maior fluxo de comércio exterior, principalmente nas exportações para países terceiros", ou seja, "maior inserção externa e melhor desempenho relativo nas vendas externas", se comparado a AAE da Terra do Fogo.
Segundo o Instituto Nacional de Estatística e Censo da Argentina - Indec, o setor industrial argentino respondeu, em 2017, por $21,8 \%$ do Produto Interno Bruto - PIB, do total de US\$637 bilhões, e emprega um quarto da população (de 45.376 .763 milhões); contudo, apesar dos 2,5\% de expansão de 2017, a produção industrial em 2018 encolheu 5\%. Os dados de 2019 apresentaram a taxa de desemprego de 9,7\% (Indec, 2019).

Na região da AAE da Terra do Fogo, além da indústria manufatureira responder a mais da metade do valor agregado, outros números são significativos. Dados de 2014 mostram o PIB per capita de US\$26.600, o que reflete em termos de indicadores sociais, e conta com a segunda melhor taxa de alfabetização do país, ou seja, 99,3\%. E, em escala global, a região atinge níveis semelhantes de PIB per capita de "economias avançadas, como a Coréia do Sul (US\$28.166), Malta (US\$25.222), Arábia Saudita (US\$24.362) ou Portugal (US\$22.122)" (GOB. AR., 2017, p. 37).

Outros dados de 2011 demonstram a menor taxa de desemprego do país, apresentando as áreas urbanas de Ushuaia e Rio Grande ( $97 \%$ da população da província) com a taxa de desemprego de $5 \%$. Ademais,

em 30 de setembro de 2016, essa taxa teve aumento de 4,6\% [...]. Os trabalhadores da Terra do Fogo têm, em média, os melhores salários de todas as províncias argentinas. Em 30 de junho de 2016, apenas $6,3 \%$ dos habitantes da província tinham renda abaixo da linha de pobreza estimada pelo Indec, consideravelmente menor que a média nacional. (GOB. AR., 2017, p. 37) 
De modo sucinto, o cenário exposto a respeito da AAE da Terra do Fogo, com seus impactos, apesar de cumprir os objetivos primordiais alusivos à ocupação, paralelamente levou à concentração urbana em Ushuaia e Rio Grande.

No outro extremo, no que toca à Zona Franca de Manaus, as mudanças pós implantação são inúmeras. A população do Amazonas cresceu 47, 2\% de 1971 a 1980; entre os anos de 1970-1985, Manaus passou de 300 mil para 800 mil habitantes e, em 2002, chegou a 1.600.000.

Os dados de 2010 mostram o Estado com 3.483.985 habitantes. Destes, 2.755.490 estão na zona urbana e 728.495 na zona rural; a capital concentrou, em 2013, 1.982.177 habitantes, em paralelo ao Estado, com 3.807.92, e, apesar da magnitude territorial, conta com pouco mais de 2 habitantes/km2. Contudo, é o maior estado brasileiro, com mais de $18 \%$ do território (IBGE, 2014).

Consequentemente, a urbanização da capital e de arredores levou à criação, em 2007, por meio da lei complementar estadual n. 52/2007, da Região Metropolitana (RM) de Manaus, composta por oito municípios e com área de 101.475 km². Em 2010, a RM de Manaus possuía "urbanização de $94 \%$ e cerca de $60 \%$ da população estadual"; sua população correspondia "a $85 \%$ da população metropolitana. A taxa de crescimento da população da RM de Manaus, entre 2000 e 2010, foi de 2,5\% ao ano" (Ipea, 2014, p. 40).

Em 2018, o faturamento da ZFM foi de $\mathrm{R} \$ 92,67$ bilhões (US\$25,35 bilhões), um aumento de $12,92 \%$, em relação a 2017 , de R\$82, 60 bilhões (US\$25,68 bilhões) (Cieam, 2018). Com esses números, se olharmos Manaus como polo dinamizador da economia regional, a despeito dos contrates entre a capital e o interior, em 2018 a cidade apresentou o maior PIB da região Norte (R\$70.296.364 bilhões), ou seja, 78,97\% de R\$98,754 bilhões do Amazonas, e representa $20,85 \%$ entre os 30 maiores municípios da região, posicionando-se com o oitavo maior PIB brasileiro (IBGE, 2019), apesar da queda no ranking nos últimos anos.

Além disso, o setor primário representa $7 \%$ de toda a riqueza produzida e teve faturamento de R\$4 bilhões de reais, em 2013; em relação aos anos anteriores, representa aumento na participação no PIB estadual, pois "saltou de 4,38 para 7\%" e, em 2018, representou R\$6,523 bilhões do PIB (Secplancti, 2019).

Das implicações, de ordem econômica ou social, a desigualdade entre a capital e os demais municípios se traduz na dependência da região em relação à ZFM, o que justifica as preocupações de sua manutenção; pois Manaus, ao concentrar mais de $50 \%$ da população, assim como da produção de riqueza, configura em um relativo isolamento geográfico da população rural ou das áreas mais longínquas, mesmo porque o Amazonas possui uma vasta extensão, o que gera agravantes no acesso a informação, bens e serviços conjugados nos entraves de logística e outros.

Os índices de empregabilidade do PIM, entre outros fatores, variam de acordo com o cenário político-econômico nacional e com oscilações da economia internacional, o que impacta em sua produção, exportações e faturamento. Segundo a Suframa, em 2018, o total de empregos entre efetivos, temporários e terceirizados registrou 86.047 mil. Em relação aos anos anteriores, esse número demonstra 0 quadro de queda, pois, em 2015, empregava o total de 118. 485 mil e, em 2014, o número de 122,114 mil (Suframa, 2019). 
Em termos políticos, para Botelho (2006), a ZFM é consenso entre os representantes do Amazonas, independentemente da orientação ideológica, e por anos reforça o lobby destes e de entidades regionais para a prorrogação dos incentivos fiscais, acirrando a discussão quando a pauta é extingui-la, em função dos custos fiscais.

Nos últimos anos, a representação em âmbito nacional moldou-se na estratégica do uso do discurso do meio ambiente e da modernização ecológica como defesa da ZFM, não somente para a região, mas para o Brasil, em razão do ciclo virtuoso de manutenção da floresta amazônica (Brianezi, 2013). Tal fato se remete a uma externalidade positiva, algo não previsto à época da implantação da ZFM, pois "encontram-se preservados $98 \%$ da cobertura florestal do Amazonas", logo "uma vantagem comparativa"16 (Puga e Botelho, 2014).

Dada a importância política e econômica, a ZFM extrapola a ideia de desenvolvimento regional e, tal como a Área Aduaneira Especial da Terra do Fogo, parte de demandas do capital internacional que fomentaram a criação e distribuição desses mecanismos pelo mundo, ou seja, "modernizou" regiões que se assentavam na produção econômica do setor primário, em muitos casos de agricultura de subsistência ou com foco no mercado local (Hobsbawn, 1995).

Destarte, as zonas francas de Manaus e da Terra do Fogo foram inicialmente definidas nos propósitos de integração, em que ameaças simbólicas, virtuais ou concretas de internacionalização são emblemáticas, seja na Amazônia (Seráfico e Seráfico, 2005), seja na Patagônia (Alvarez, 2016). A produção voltada ao mercado nacional, moldada na política de industrialização de substituição de importação, alinhada ao fator de integração geopolítica, desponta como um dos propósitos iniciais, e com o tempo as zonas francas passaram por várias adaptações.

Enquanto mecanismos indutores de desenvolvimento econômico regional, as zonas francas não alcançaram a autonomia plena e se atêm presas à oferta de incentivos, pois, em meio às prorrogações (AAE da Terra do Fogo até 31/12/2023 e a ZFM até 2075). Além dos fatores de ordem política, outros problemas são recorrentes, como, por exemplo, elas sofrem com os gargalos de logística, devido às peculiaridades de localização, e podem esbarrar nas questões de conectividade físicas e/ou virtuais e nas questões de inserções às CGV e de novos desafios da intensa circulação de fluxos, pessoas, ideias, conhecimento, mercadorias, que podem resultar em variados e inimagináveis efeitos.

\section{Zonas Francas, Cadeias Globais de Valor e a conectividade dos lugares}

Em um contexto de intensa competitividade, as formas como as zonas francas estruturam-se devem responder aos novos e constantes desafios do mundo, cada vez mais regido por conexões de ordem das infraestruturas física ou virtual.

Destarte, é possível ponderá-las no conceito de aglomerados ou clusters de Porter (2009, p. 211), que se constituem na "concentração geográfica de empresas inter-relacionadas e instituições correlatas", composta por "fornecedores especializados, prestadores de serviços e instituições específicas 
(universidades, institutos de pesquisa, órgãos de normatização e associações comerciais), vinculadas por elementos comuns e complementares, que competem e cooperam entre si.

Embora o conceito de cluster se contextualize, em termos de competitividade dos países, também "depende da capacidade da sua indústria de inovar e melhorar" e se torna útil para pensar em termos de zonas francas, pois, para o autor, o conhecimento da situação dos aglomerados "numa localidade proporciona importantes insights sobre o potencial produtivo da economia local e sobre as limitações ao seu desenvolvimento futuro (ibid., p. 167).

Porter (ibid., pp. 267-268) observa que os IDE, zonas de livre comércio e os parques industriais nos PED funcionam como "alavancas no favorecimento do crescimento dos aglomerados", pois desfrutam de melhores condições de fomento específicos e, apesar de talvez terem iniciado em um "ambiente de negócios em geral ineficiente [...] com o tempo essas zonas constroem elos com a economia em geral".

Um estudo do Instituto de Pesquisas Aplicadas - Ipea sobre cadeias globais de valor $^{17}$ sublinha, como resultado importante das políticas industriais, a criação de clusters industriais e ZEEs, descrevendo-os "como mecanismo para aumento da competitividade com efeitos sobre o desenvolvimento da região" e "instrumento eficiente para a inserção dos países nas CGV" (Pinto et al., 2017, p. 63). Para ilustrar o estudo, cita os exemplos da China, Malásia, Vietnã e México; cabendo lembrar que, em 2018, esses países, com exceção do México, estavam entre as maiores taxas de crescimento do mundo (Khanna, 2019). ${ }^{18}$

Nesse viés, segundo o Relatório sobre o Desenvolvimento Mundial de 2020 para o funcionamento das CGV "as políticas são importantes - tanto para aumentar a participação como para ampliar os benefícios" (WDR, 2020 , p. III). Este tipo de visão é explanado pelo o estudo do Ipea, segundo o qual ao Estado cabe sua importância na regulação das políticas industriais (Pinto et al., 2017), o que atesta ser relevante na difusão das zonas francas pelo mundo e no impulso de fortalecimento das CGV.

Desse modo, o enfoque nas zonas francas elucida o engajamento dos Estados em atrair IDE, o que pode configurar na concorrência entre os Estados em oferecerem melhores atrativos às empresas (Dupas, 2005). Logo, territórios, em particular Estados-nação, devem ser competitivos. Para o geógrafo Ardinat (2012), essa liminar de desempenho parece se aplicar a todos os aspectos da sociedade.

Com um olhar crítico, o estudo geográfico da competitividade ${ }^{19}$ de Ardinat (ibid.) mostra como a "competitividade" "tornou-se onipresente no discurso público"; segundo ele, o livre comércio, um dos componentes da globalização, marcado pela competição e circulação sem entraves de bens e serviços, parece envolver as regiões em uma "competição multifacetada", fruto da natureza competitiva da economia mundial. Destarte, como problema, a competitividade emerge como preocupação no planejamento regional e política econômica dos países, o que influencia políticas econômicas e sociais, planejamento e estratégias industriais.

Para o autor, a competição de territórios forja uma competição geral:

entre empresas, entre sistemas sociais, tributação, infraestruturas e funcionários. Ao aplicar o dogma da competição a entidades geográficas (como aglomerações, regiões ou nações), 
a competitividade muda o significado de

"território": tradicionalmente definido como um espaço delimitado por uma fronteira e carregado de cultura, história e sentimentos, o território competitivo parece ter se tornado um simples objeto de competição medido de acordo com sua eficiência produtiva. (Ibid., p. 115)

A referida "eficiência produtiva" aferida por índices e ferramentas dos rankings de relatórios, como do Fórum Econômico Mundial - FEM (Relatório de Competitividade Global) e do International Institute for Management Development - IMD Business School (Anuário da Competitividade Mundial) ou do Banco Mundial (Doing Business), para Ardinat (ibid., p. 119), muitas vezes, "ignora a falta de homogeneidade na distribuição dos determinantes da competitividade" dos países, porque muitos desses países operam em várias escalas, o que pode deixar lacunas na compreensão das especificidades do espaço econômico. Segundo o autor, "as políticas nacionais de competitividade têm de lidar simultaneamente com as exigências de autonomia das regiões e influência externa de poderes supranacionais".

Com outro enfoque, baseado na complexidade econômica dos países, Gala (2017, p. 41) situa a relevância do Estado no crescimento da Ásia, que se trata da soma do "direcionamento estatal" e da "iniciativa privada competente e eficiente". Para o autor, a literatura econômica tem discutido a questão, e um dos pontos de convergência se dá no foco da região na diversificação de "bens comercializáveis de não commodities, o que contribuiu para a acumulação de capital e inovações tecnológicas".
Aliados às políticas contracionista, alguns países asiáticos "lançaram mão de uma política cambial competitiva para atenuar os feitos negativos de liberalizações comerciais"; alguns países foram mais ousados no estímulo das exportações com desvalorização cambial (taxa de câmbio flutuante), integrando-se às políticas industrial, fiscal e monetária numa estratégia geral de export-led-growth (ibid., p. 74).

Essas são as premissas com as quais as ZEEs de Cingapura, Hong-Kong, Coréia do Sul, Taiwan, Indonésia, Malásia e Tailândia podem ser vistas. Tal como a América Latina, inicialmente se pontuaram na política de substituição de importação, a fim de estimularem o mercado doméstico, porém mudaram a estratégia de industrialização com promoção para as exportações - EPI, ou seja, "na promoção deliberada de manufaturas" voltada para exportações (ibid., p. 74) .

Segundo Gala (ibid.), consiste no regime de comércio e na administração macroeconômica que, na América Latina, foi marcada pela apreciação cambial (valorização da moeda doméstica), enquanto os países da Ásia fizeram o inverso (desvalorização da moeda), mediante a necessidade de adquirir divisas, a fim de se tornarem mais competitivos no mercado mundial.

A experiência asiática que surgiu da estratégia de especialização de produção de manufaturas exportadoras mostra que alguns países saíram da categoria de "montadores" para a complexidade de suas economias e conseguiram diversificar a pauta de exportações, despontando na criação de empresas globais de capital nacional, nos setores de eletrônicos, autopeças, automóveis, aliada a medidas de adoção de joint-ventures com os investidores estrangeiros, objetivando assegurar 
transferência de tecnologias ou prática de engenharia reversa; que, nesses países, permitiu-se, de certa forma, imitar tecnologias sem sanções rigorosas (ibid.).

Esse quadro analisado mediante os dados da complexidade dos países está relacionado à ubiquidade e à diversidade de produtos exportados dos países; assim, se determinada "economia é capaz de produzir bens não ubíquos, raros e complexos" tem-se a "indicação de que o país tem um sofisticado tecido produtivo" (ibid., p. 22), ou seja, condição para atingir um alto nível de produção per capita.

Diante da questão, para o autor, "o desenvolvimento econômico pode ser tratado como o domínio de técnicas produtivas mais sofisticadas, que em geral levam à produção de maior valor adicionado por trabalhador, como defendiam os clássicos" (ibid., p. 25). Dessa forma, a visão complementa-se em relação aos "padrões de especialização dos países no comércio mundial: países ricos (centro) especializam-se em mercados de competição imperfeita e países pobres, periferia, em mercados de competição perfeita" (ibid.), premissa assinalada pelos clássicos do desenvolvimento econômico. Tal relação, se analisada por meio da complexidade econômica, pode lançar luz sobre as condições de implantação e funcionamento de zonas francas em diversos contextos e ajuda a elucidar o desenvolvimento econômico de países como a China e suas estratégias de ascensão econômica e suas inserções nas CGV.

Contudo, o estudo do Ipea supracitado ressalta que nem todos os países se beneficiam com o uso desses mecanismos. Há casos em que contribuem "somente para a fase de inserção e maior participação nas cadeias, sem efeito de encadeamento sobre o restante da economia, e sem contribuir também para o deslocamento do país para atividades de maior valor adicionado" (Pinto et al., 2017, p. 64).

A participação em CGV, de acordo com o Relatório de Desenvolvimento Mundial de 2020, é determinada "pelas dotações, de fatores, geografia, tamanho do mercado e instituições" e necessita das políticas de atração de IDE como meio de atenuar "a escassez de capital, tecnologia e qualificações de gestão", entre outros instrumentos, como "abertura comercial e ou/isenções fiscais e subsídios", no sentido de disponibilizar "proteção dos investidores, estabilidade, um ambiente de negócios favorável", em alguns casos, forjado na promoção do investimento que visam a superar diversas limitações, correlacionadas à melhoria da infraestrutura de transportes e comunicações entre outros (WDR, 2020, p. 5).

Por outro viés, a noção de "cadeias de suprimentos", de Khanna, ajuda a pensar a importância das zonas francas, pois elas criam "oportunidades econômicas onde não existiam, trazendo ideias, tecnologias e práticas comerciais para locais que não possuem as vantagens e um bom clima e solo ou outras variáveis propícias". Desse modo, incluem-se em uma dinâmica entendida, pelo autor, como "conectividade" dos lugares. Ele observa que, embora "um país não possa mudar onde está, a conectividade oferece uma alternativa ao destino da geografia" (Khanna, 2016, s. p.).

A organização global impulsionada cada vez mais pela conectividade econômica sobrepõe-se ao peso da divisão política e sugere que o mundo passa por uma transformação em que a importância da "infraestrutura funcional diz mais sobre como o mundo funciona, além das fronteiras políticas". Ou seja, as economias estão cada vez mais definidas pela "geografia 
funcional", na qual regiões estão ligadas por cadeias de suprimentos e linhas de infraestrutura que transcendem políticas comuns, os limites territoriais tradicionais, como estados e nações (ibid.).

0 exemplo das megacidades (podem ser grupos de várias grandes cidades), como o corredor da Costa Leste dos EUA (Boston, Nova York e Washington, D.C.), ilustra como servem de âncoras para suas regiões e seus líderes, pois cresceram correspondentemente em poder e governança, o que também afeta a infraestrutura que une as regiões. Segundo Khanna (2016, s. p.), tais cidades contêm o cérebro acadêmico, o centro financeiro e o capital político dos Estados Unidos. Assim, na composição de infraestruturas funcionais e na criação da complexa cadeia de suprimentos, à medida que "acumulam finanças, tecnologia, diversidade e vitalidade", não é o tamanho da população ou do território que influencia o mundo:

mas cidades, o peso econômico, proximidade de zonas de crescimento, onde a estabilidade política importa mais que o tamanho e soberania. Nova York, Dubai e Hong Kong não são capitais nacionais, mas estão entre as cinco principais cidades do mundo em termos de fluxos que passam por elas. (Ibid.)

Diante das premissas, economias dinâmicas são aquelas que se apropriam com mais eficiência das vantagens da "geografia funcional e incentivam o alinhamento econômico com base nessas tendências", e o aproveitamento de "ferramentas tradicionais", como as ZEEs, alinham-se a novos paradigmas e estruturas políticas e econômicas que servem "para capitalizar esses desenvolvimentos" (ibid.).
Desse modo, ao contribuírem na formação das redes globais, exercida em suas conexões econômicas, por exemplo, Hong Kong e Dubai, as cidades globais e as zonas francas, para Khanna (ibid.), "importam mais do que os estados", e as cadeias de suprimentos das quais dispõem "serão uma fonte de poder mais importante que as forças armadas - cujo principal objetivo será proteger as cadeias de suprimentos em vez das fronteiras". Esses espaços subnacionais nos ajudam a pensá-los como lugares nos quais ganham vida as conexões de formas cada vez mais recorrentes.

\section{Considerações finais}

Para Seráfico (2009), como mecanismos artificialmente construídos, as zonas francas compõem parte do processo de configuração global do capitalismo e resultam do processo de desterritorialização técnica e social dos modos de produção e territorialização de espaços. Sassen (1998 e 2010) as apresenta como espaços subnacionais que compõem pontes entre a escala global e local, com escalonamentos estratégicos de "desnacionalização de certos componentes do território nacional" e, tal como as cidades globais, constituem o locus para se entender o global relacionado a vários processos de produção para a globalização econômica.

Nesse sentido, cidades como Manaus ou que possuem zonas francas, constituem lugares diferenciados nas regiões onde se encontram. Assim, despertam a questão relacionada "ao papel do lugar em muitos circuitos que constituem a globalização econômica e 
política". Embora localizadas em territórios nacionais, as zonas francas envolvem processos nos quais as "estruturas nacionais existentes não necessariamente são capazes de regular suas funções" (Sassen, 2010, p. 21).

Assim, o panorama geral das zonas francas apresentado neste artigo possibilita perceber os caminhos que se traçaram a partir das dinâmicas e tendências específicas da economia global, além de serem responsáveis pela inserção internacional de várias economias nacionais que buscavam o desenvolvimento e crescimento econômico. 0 recorte com a ZFM e a AAE/TDF mostra que estão expostas as revisões de seus conceitos ligados ao funcionamento de regimes especiais, como também se esbarram no fato de se localizarem no Mercosul, ${ }^{20}$ o que as expõem nas diretrizes desse mercado (Suframa, 2014 , s. p.) e dos desdobramentos da economia internacional.
Entre os resultados, os indicadores socioeconômicos mostrados da Zona Franca de Manaus e da Área Aduaneira da Terra do Fogo pontuaram o crescimento econômico e demográfico, geração de emprego, entre outros dados, que, de modo amplo, também são reflexos dos instrumentos de estabilização da economia decorrentes das políticas monetária, fiscal e cambial de seus países.

Outras questões emergem. Se, de um lado, objetivaram amenizar as desigualdades de desenvolvimento regional; mas, de outro, incidiram as críticas sobre o peso tributário ou sobre a renúncia fiscal e a dependência moldada em uma industrialização exógena, que não conseguiu estimular o desenvolvimento de suas potencialidades locais, pois baseia-se em uma matriz tecnológica de complexidade limitada, se comparada à zona franca de Shenzhen de produção voltada à produção de desenvolvimento de alta tecnologia.

\section{[I] https://orcid.org/0000-0002-0008-9522}

Universidade Federal do Amazonas, Faculdade de Estudos Sociais, Departamento de Economia e Análise. Manaus, AM/Brasil.

costanara@hotmail.com 


\section{Notas}

(1) Refere-se ao crescente volume de dados disponíveis com grande velocidade do mundo digital.

(2) Os antigos economistas do desenvolvimento, também conhecidos como estruturalistas, dividiam-se em duas correntes principais: anglo-saxã e latino-americana, "baseavam suas análises sobre o desenvolvimento nos conceitos de linkages ou ligações produtivas, armadilhas de pobreza e dualismos. A visão estruturalista define o desenvolvimento econômico como uma transformação radical na estrutura produtiva das economias, sofisticando o tecido produtivo" (Gala, 2017, p. 19).

(3) O Relatório de Investimento Mundial (publicação anual da Conferência das Nações Unidas para o Desenvolvimento e Comércio - Unctad) apresentou como tema, em 2019, as Zonas Econômicas Especiais, trazendo um mapeamento universal e atualizado das zonas francas em geral (WIR, 2019).

(4) O número de ZEE é indefinido. Uma das razões para isso está na ausência de uma definição padrão (WIR, 2019).

(5) Do total,10\% foram anunciados e deverão abrir nos próximos anos (WIR, 2019, p. 137).

(6) São centros bancários extraterritoriais, que "oferecem certos tipos de flexibilidade adicional: sigilo, abertura para o dinheiro 'quente' e certas opções 'legítimas', não inteiramente permitidas nos mercados desregulamentados dos centros financeiros" (Sassen, 2000, p. 29).

(7) Forma organizacional de cadeia contínua implica submissão à cadência do conjunto da máquina, estandardização das peças e produtos na fabricação de produtos baratos, produzidos e vendidos em massa. A concessão de salários elevados ultrapassa o domínio da organização do trabalho e corresponde à lógica de crescimento no nível macroeconômico. É uma regulação que manteve o aumento da demanda sem baixa das taxas de lucro. A intervenção do Estado e o desenvolvimento dos acordos entre parceiros sociais nos países industrializados pós 1945 favoreceram o aumento regular da demanda, condição necessária desse modo de regulação, e declinou no começo dos anos 1970 (Benko, 1999, p. 236).

(8) Onde se realizavam quase todas as etapas do processo produtivo de forma verticalizada de gestão, baseada na coordenação hierarquizada desse processo (Benko, 1999).

(9) Conhecida por Nova Rota da Seda é uma referência à antiga Rota da Seda. Consiste no plano de ajuda mútua, no qual a China deverá, ao longo dos anos, investir U\$\$1 trilhão no exterior (126 países) para o desenvolvimento de novas rotas de comércio terrestre (cinturão) e marítimos (rota) ao redor do mundo. São investimentos em infraestrutura física: estradas, ferrovias, portos, aeroportos, fibras óticas, dutos, usinas de energia e, também, em projetos educacionais, digitais, esportivos e capital humano. Quanto às promessas de empréstimos, são U\$\$345 bilhões do governo chinês; U\$233 bilhões do Banco Estatal Chinês; U\$40 bilhões do Fundo da Estrada da Seda da China; U\$100 bilhões do Banco Asiático de investimento em Infraestrutura; e U\$59 bilhões do Banco Mundial (Geromel, 2019; Khanna, 2016).

(10) A primeira fase começou a funcionar em 2018, trata-se de uma joint venture com o governo de Djibuti (maior acionista) e mais 3 empresas chinesas: China Merchants Group, Dalina Port Autoridade e IZP.

(11) Fauna e flora abundante, recursos minerais diversos, entre outros. 
(12) A história econômica da Amazônia correlaciona-se aos produtos naturais; drogas do sertão, borracha, extração de castanha, madeira, minérios ou até da agricultura de subsistência local (pouca expressividade de excedente para exportação). O ciclo do látex colocou a região como a segunda zona econômica mais importante do País, que declinou a partir de 1912; com a II Guerra Mundial, ela retoma novo impulso, em razão do déficit dos EUA de matéria-prima, porém sem lograr o êxito anterior.

(13) O governo ditatorial argentino compreende 1966-1973 e 1976-1983 e, no Brasil, de 1964 a 1985.

(14) Querela com o Chile resolvida em 1984.

(15) Soberania compartilhada com o Chile. Na Argentina, chama-se Província da Terra do Fogo, Antártica e Ilhas do Atlântico Sul (Lei n. 23.775 de "Provincialização do último território nacional").

(16) A questão do aquecimento global coloca a Amazônia entre as prioridades no desenvolvimento econômico mundial; sua preservação não se trata de uma questão particular ou localizada, mas de uma questão global (Puga e Botelho, 2014, p. 143).

(17) A CGV divide o processo de produção entre os países; as empresas se especializam em uma tarefa e não produzem todo o produto. Matérias-primas/Insumos de serviços (Exportações/ fronteira) - Peças e componentes/produtos semiacabados (Exportações/fronteira) - Produtos acabados (Exportações para o consumo). O tipo de vinculação do país com as CGV baseia-se em: 1) extensão da participação na CGV; 2) especialização setorial do país no comércio e 3) grau de inovação (WDR, 2020).

(18) Acrescentam-se, no grupo, a Índia, Indonésia e Uzbequistão. Cabe expor que a China se tornou a maior economia do mundo (em termos de Paridade de Poder Compra - PPC) em 2014 (Khanna, 2019).

(19) A "competitividade territorial" remete observar a globalização e sua organização hierárquica de espaços produtivos. Faz parte da tradição de classificação de países. Essas hierarquias podem lidar com questões muito diferentes, mas a metodologia subjacente é muito semelhante: índices compostos que reúnem muitas variáveis; apesar dos vários estudos, há pouca variação na geografia global dos vencedores econômicos e sociais, o que corrobora a visão hierárquica e padronizada da globalização (comercializável e elitista do mundo) (Ardinat, 2012).

(20) É um processo de integração econômica entre: Argentina, Brasil, Venezuela, Uruguai e Paraguai. A Venezuela está temporariamente suspensa.

\section{Referências}

ALVAREZ, G P. (2016). Amazônia brasileira e Patagônia Argentina: planos de desenvolvimento e soberania nacional. Estudos Avançados. São Paulo, v. 30, n. 88, pp. 117-138.

ARDINAT, G. (2012). Compétitivité, territoires et échelles de gouvernance: I'exemple canadien. Études sociales/Canadian Studies, v. 72, pp. 115-126.

ARTHUR, W. B. (2013). Complexity economics: a different framework for economic though. Santa Fe, Santa Fe Institute. 
BECKER, B. (2005). Geopolítica da Amazônia. Estudos Avançados. São Paulo, v. 19, n. 53, pp. 71-86.

BEKERMAN, M; DULCICH, F. (2016). Políticas productivas en la postconvertibilidad: el caso de Tierra del Fuego y su comparación con la zona franca, de Manaos de Brasil. CEDEE. Buenos Aires, Universidad de Buenos Aires, Doc. Trab. 24, pp. 1-70.

(2017). Análisis comparativo de la Zona Franca de Manaos y el área aduanera especial de Tierra del Fuego. Economia e Sociedade. Campinas, v. 26 n. 3, pp. 751-791.

BENKO, G. (1999). Economia, espaço e globalização na aurora do século XXI. São Paulo, Hucitec.

BOTELHO, A. J. (2006). Redesenhando o projeto Zona Franca de Manaus. Manaus, Valer.

BRAGA, H. C. (1995). Zonas de Processamento de Exportação: avaliação e perspectivas. FUNCEX. Texto de Discussão, n. 144, pp. 1-23.

BRIANEZI, T. (2013). O deslocamento do discurso sobre a Zona Franca de Manaus: do progresso à modernização ecológica. Tese de doutorado. São Paulo, Universidade de São Paulo.

BRITO, D. C. (2001). A modernização da superfície: estado e desenvolvimento na Amazônia. Belém, UFPA/Naea/PDTU.

CASTELLS, M. (2006). Sociedade em rede - A era da informação: economia, sociedade e cultura. São Paulo, Paz e Terra, vol. 1

CHESNAIS, F. (1996). A mundialização do capital. São Paulo, Xamã.

CIEAM (2018). PIB de Manaus tem crescimento de 4,8\%., mas capital cai em lista de concentração de riquezas. Centro da indústria do estado do Amazonas. Disponível em: https://cieam.com. br/?u=pib-de-manaus-tem-crescimento-de-4_8_-mas-capital-cai-em-lista-de-concentracao-deriquezas. Acesso em: 20 set 2019.

DUPAS, G. (2005). Atores e poderes na nova ordem global: assimetrias, instabilidades e imperativos de legitimação. São Paulo, Editora Unesp.

FIAS (2008). Special Economic Zones. Performance, Lessons learned, and implications for zone development. Washington, DC, Facility for Investment Climate Advisory Services - FIAS Annual Review, World BankGroup.

FREITAS PINTO, E. R. (1987). Como se produzem as zonas francas. Belém, UFPA/Núcleo de Altos Estudos Amazônicos. Série Seminários e Debates, n. 13, pp. 19-39.

GALA, P. (2017). Complexidade econômica: uma nova perspectiva para entender a antiga questão da riqueza das nações. Rio de Janeiro, Contraponto.

GEROMEL, R. (2019). O Poder da China: o que você precisa saber sobre o país que mais cresce em bilionários e unicórnios. São Paulo, Gente (edição Kindle).

GOB.AR. (2017). Invertir en Tierra del Fuego: tierra de oportunidades. Ushuaia, Secretaría de Desarrollo e Inversiones. Gobierno de Tierra del Fuego, Antártida e Islas del Atlántico Sur República Argentina, v. 1, pp. 1-81.

HAUSMANN, R. et al. (2013). The Atlas of Economic Complexity: Mapping paths to prosperity. Cambridge, MIT Press. Disponível em: http://www.tinyurl.com/y67m6n72. Acesso em: 27 out 2019.

HOBSBAWN. E. J. (1995). A Era dos Extremos: o breve século XX 1914-1991. São Paulo, Companhia das Letras. 
IBGE (2014). Pesquisa Nacional por Amostra de Domicílios: síntese de indicadores 2010. Rio de Janeiro, Instituto Brasileiro De Geografia e Estatística. Disponível em: http://www.ibge.gov.br/estadosat/ perfil.phpsigla=am. Acesso em: 21 jan 2014.

(2019). Cidades. Disponível em: https://cidades.ibge.gov.br/brasil/am. Acesso em: 14 out 2019.

ILO (2003). Employment and social policy in respect of export processing zones (EPZs). Governing Body, n. 286th Session, Geneva, ILO Publications, pp. 1-24.

INDEC (2019). Anuario Estadístico de la Republica Argentina 2018. Serie Análisis Demográfico n. 33. Instituto Nacional de Estatística e Censo da Argentina. Disponível em: https://www.indec.gob. ar/. Acesso em: 29 jan 2020.

IPEA (2014). Atlas do Desenvolvimento Humano nas Regiões Metropolitanas Brasileiras. IPEA, FJP e PNUD. Brasília. Disponível em: http://www.ipea.gov.br/portal/index.php?option=com_ content\&id=24037. Acesso em: 8 out 2019.

KHANNA, P. (2016). Connectography: mapping the global network revolution. New York, W\&N. Edição Kindle

(2019). The future is Asian. Commerce, conflict and culture in the 21st Century. Nova York, Simon \& Schuster (edição Kindle).

MAHAR, D. J. (1978). Desenvolvimento econômico da Amazônia: uma análise das políticas governamentais. Rio de Janeiro, Ipea/Inpes.

MICHALET, C. A. (2003). O que é a mundialização. São Paulo, Loyola.

PINTO, E. et al. (2017). “Dimensões da abordagem da cadeia global de valor: upgrading, governança, políticas governamentais e propriedade intelectual”. In: OLIVEIRA, I. T. M; CARNEIRO, F. L; SILVA FILHO, E. B. (orgs.). (2017). Cadeias globais de valor, políticas públicas e desenvolvimento. Brasília, Ipea.

PORTER, M. E. (2009). Competição on competition: estratégias competitivas essenciais. São Paulo, Campus.

PUGA, F, S. M.; BOTELHO, L. (2014). O emprego industrial na Região Norte: o caso do Polo Industrial de Manaus. Estudos Avançados. São Paulo, v. 28, n. 81, pp. 141-154.

SASSEN, S. (2000). Cities in a World Economy. London/New Delhi, Pine Forge Press. (2010). Sociologia da globalização. Porto Alegre, Artmed.

SECPLANCTI (2019). Produto Interno Bruto 2018. Manaus, Secretaria de Planejamento, Desenvolvimento, Ciência, Tecnologia e Inovação, Governo do Amazonas.

SERÁFICO, M. (2009). O empresariado local e a zona franca de Manaus: reprodução social e globalização econômica. Tese de doutorado em Sociologia, Porto Alegre, Universidade Federal do Rio Grande do Sul.

SERÁFICO, M.; SERÁFICO, J. (2005). A Zona Franca de Manaus e o capitalismo no Brasil. Estudos Avançados. São Paulo, v. 19, n. 54, pp. 99-113.

SKLAIR, L. (1989).Assembling for development: the maquila industry in México and The United States. Londres, Routledge,

(1995). A Sociologia do sistema global. Petrópolis, RJ, Vozes. 
SUFRAMA (2014). Zona Franca de Manaus e Terra do Fogo buscam maior cooperação. Disponível em: http://site.suframa.gov.br/noticias/zona-franca-de-manaus-e-terra-do-fogo-buscam-maiorcooperacao. Acesso em: 14 jan 2019.

(2019). Faturamento 2018. Disponível em: http://site.suframa.gov.br/noticias/polo-industrialde-manaus-fatura-r-94-bilhoes-em-2018. Acesso em: 10 jun 2019.

VIVES, L. M. (2000). Las zonas francas: aspectos: jurídicos, tributários, aduaneiros, comerciais e operativos. Buenos Aires, Errepar.

WDR (2020). Relatório sobre o Desenvolvimento Mundial de 2020: o comércio para o desenvolvimento na era das cadeias globais de valor. Washington, DC, World Bank Group. Disponível em: www. worldbank.org. Acesso em: 20 fev 2020.

WIR (2019). World Investment Report 2019: Special Economic Zones. Nova York, UN/ UNCTAD Publications. Disponível em: un.org/publications. Acesso em: 10 out 2019.

Texto recebido em $2 / \mathrm{mar} / 2020$

Texto aprovado em 15/abr/2020 